\title{
Caracterización fisicoquímica de almidones de tubérculos cultivados en Yucatán, México
}

\author{
Caracterização físico-química de amidos de tubérculos cultivados em Yucatán, México
}

\author{
Marilyn HERNÁNDEZ-MEDINA', Juan Gabriel TORRUCO-UCO ${ }^{1}$, \\ Luis CHEL-GUERRERO ${ }^{1}$, David BETANCUR-ANCONA ${ }^{1 *}$
}

\begin{abstract}
Resumen
Se realizó la evaluación de las propiedades fisicoquímicas y funcionales de almidones de tubérculos: makal (Xanthosoma yucatanensis), camote (Ipomea batata), yuca (Manihot esculenta Crantz) y sagú (Marantha arundinacea). El tamaño promedio de los gránulos de almidón varió de 10,6 a 16,5 $\mu \mathrm{m}$. La amilosa fue de 23,6, 19,6, 17,0 y 22,7\%, para el makal, camote, yuca y sagú. Las temperaturas de gelatinización fueron de $78,4,61,3,65,2$ y $74,9^{\circ} \mathrm{C}$, respectivamente. El almidón de yuca fue el que presentó mayor poder de hinchamiento y solubilidad. La viscosidad máxima fue para el almidón de yuca. El almidón de camote presentó la mayor claridad de gel (51,8\%) y el de makal, la menor $(10,9 \%)$. El almidón de yuca fue el más elástico $(36,2 \%)$. Los almidones de makal y de sagú pueden ser utilizados en productos que requieren altas temperaturas de procesamiento. Los almidones de camote y de yuca pueden ser incluidos en sistemas alimenticios como espesantes, estabilizantes y gelificantes en alimentos refrigerados y congelados.

Palabras-clave: almidón; makal; camote; yuca; sagú; propiedades funcionales.
\end{abstract}

\section{Resumo}

Foram avaliadas as propriedades físico-químicas e funcionais de amidos dos seguintes tubérculos: makal (Xanthosoma yucatanensis), batata-doce (Ipomea batata), mandioca (Manihot esculenta Crantz) e araruta (Marantha arundinacea). O tamanho médio dos grânulos de amido variou de 10,6 a 16,5 $\mu \mathrm{m}$. A amilose foi de 23,6, 19,6, 17,0 e 22,7\%, para makal, batata-doce, mandioca e araruta. As temperaturas de gelatinização foram de $78,4,61,3,65,2$ e $74,9^{\circ} \mathrm{C}$, respectivamente. $\mathrm{O}$ amido de mandioca foi o que apresentou maior poder de inchamento e solubilidade. A viscosidade máxima foi para o amido de mandioca. $\mathrm{O}$ amido de batata-doce apresentou a maior claridade de gel (51,8\%) e o amido de makal, a menor (10,9\%). O amido de mandioca foi o mais elástico (36,2\%). Os amidos de makal e de araruta podem ser utilizados em produtos que requerem altas temperaturas de processamento. Os amidos de batata-doce e de mandioca podem ser incluídos em sistemas alimentícios como espessantes, estabilizantes e geleificantes, em alimentos refrigerados e congelados.

Palavras-chave: amido; makal; batata-doce; mandioca; araruta; propriedades funcionais.

\section{Introducción}

El almidón es una materia prima con un amplio campo de aplicaciones que van desde la impartición de textura y consistencia en alimentos hasta la manufactura de papel, adhesivos y empaques biodegradables (ZHAO; WHISTLER, 1994). Debido a que el almidón es el polisacárido más utilizado como ingrediente funcional (espesante, estabilizante y gelificante) en la industria alimentaria, es necesario buscar nuevas fuentes de extracción, ya que con una producción mundial de 48,5 millones de ton/año (FAOSTAT, 2001), existe una demanda insatisfecha del mismo.

De las calorías consumidas por los humanos, cerca del 70 al $80 \%$ provienen del almidón. Es la principal fuente de almacenamiento de energía en los vegetales, ya que se encuentra en grandes cantidades en las diversas variedades de plantas, como, por ejemplo, en los granos de cereales, los cuales contienen entre 60 y 75\% de su peso seco de almidón, así como también, puede encontrarse en tubérculos, semillas de leguminosas y en algunas frutas, y su concentración varía con el estado de madurez de los mismos (THOMAS; ATWELL, 1999).

Estructuralmente, el almidón consiste de dos polisacáridos químicamente distinguibles: la amilosa y la amilopectina. La amilosa es un polímero lineal de unidades de glucosa unidas por enlaces $\alpha$ (1-4), en el cual algunos enlaces $\alpha$ (1-6) pueden estar presentes. Esta molécula no es soluble en agua, pero puede formar micelas hidratadas por su capacidad para enlazar moléculas vecinas por puentes de hidrógeno y generar una estructura helicoidal que es capaz de desarrollar un color azul por la formación de un complejo con el yodo (KNUTZON; GROVE, 1994). Mientras que la amilopectina es un polímero ramificado de unidades de glucosa unidas en un $94-96 \%$ por enlaces $\alpha$ (1-4) y en un 4-6\% con uniones $\alpha$ (1-6). Dichas ramificaciones se localizan aproximadamente a cada 15-25 unidades de glucosa. La amilopectina es parcialmente soluble en agua caliente y en presencia de yodo produce un color rojizo violeta (GUAN; HANNA, 2004).

Recebido para publicação em 27/9/2007

Aceito para publicação em 9/4/2008 (002894)

${ }^{1}$ Facultad de Ingeniería Química, Universidad Autónoma de Yucatán. Av. Juarez, 421, Cd. Industrial, CP 97288, Apdo. Postal 1226-A, Mérida, Yucatán, México

E-mail: bancona@uady.mx

${ }^{*}$ A quem a correspondência deve ser enviada 
Los almidones nativos de las diferentes especies de vegetales tienen como característica fundamental que sus propiedades fisicoquímicas y funcionales estarán influenciadas por sus estructuras granular y molecular (WANG; WHITE, 1994a). Las propiedades más importantes a considerar para determinar la utilización del almidón en la elaboración de alimentos y otras aplicaciones industriales incluyen las fisicoquímicas: gelatinización y retrogradación; y las funcionales: solubilidad, hinchamiento, absorción de agua, sinéresis y comportamiento reológico de sus pastas y geles (WANG; WHITE, 1994b).

Los gránulos de almidón se encuentran en un sistema polimérico semicristalino, donde la cristalinidad varía de 15 a 45\%, y es atribuida a las cadenas cortas lineales de la amilopectina, que forman dobles hélices organizadas en una estructura cristalina tridimensional (ZOBEL, 1988; EERLINGEN; DELCOUR, 1995). Durante el proceso de gelatinización, el orden molecular dentro de los gránulos es destruido gradual e irreversiblemente, por esto la temperatura de gelatinización es característica para cada tipo de almidón y depende fundamentalmente de la transición vítrea de la fracción amorfa del almidón (EERLINGEN; DELCOUR, 1995). Algunos eventos ocurren durante el proceso: el orden molecular, y por lo tanto la birrefringencia, se pierde; los gránulos pierden su cristalinidad, absorben gran cantidad de agua, provocando el hinchamiento y un aumento en su volumen. Se solubilizan algunas moléculas, particularmente la amilosa, que se difunde hacia el agua y, si el calentamiento continúa, se rompen y se observa una solubilización parcial. Todo este proceso es endotérmico, requiriéndose aproximadamente $10 \mathrm{~mJ} . \mathrm{mg}^{-1} \mathrm{de}$ almidón para efectuarlo, como lo han demostrado los estudios con Calorimetría Diferencial de Barrido (CDB) (BILIADERIS, 1992). La pasta de almidón obtenida después de la gelatinización no es estable, ya que durante el almacenamiento se presentan transformaciones estructurales que, en conjunto, reciben el nombre de retrogradación.

En virtud de que las fuentes convencionales más importantes para la extracción de este polisacárido son los granos de cereales como el maíz, trigo, arroz y sorgo; tubérculos como la papa, yuca, boniato y sagú; encontrándose también en hojas, semillas de leguminosas y frutas (BETANCUR-ANCONA et al., 2004), la tendencia actual es buscar fuentes no convencionales como alternativas para obtener almidones que presenten diversas características fisicoquímicas, estructurales y funcionales, que amplíen la gama de usos en la industria. Entre las materias primas que pueden ser utilizadas como nuevas fuentes de extracción de este polímero se encuentran los tubérculos, ya que estos juegan un papel significativo en el sistema global de alimentación y contribuyen a los requerimientos energéticos de más de 2 millones de personas en los países en vías de desarrollo. Los cultivos más importantes de raíces y tubérculos a nivel mundial son la yuca (Manihot esculenta), batata (Ipomea batata), papa (Solanum tuberosum), ñame (Dioscorea spp.), ocumo (taro, ayutia $=$ Colocasia esculenta) y tannia (Xanthosoma spp.). En conjunto, estos cultivos ocupan cerca de 50 millones de hectáreas en el mundo (CIAT, 1997).

En la Península de Yucatán en México, las raíces y tubérculos que se cultivan en las milpas de los agricultores son de origen americano. Cuatro se cultivan desde antes de la conquista (el makal, el camote, la yuca y la jícama) y las otras dos (el sagú y la papa), aunque americanas, fueron introducidas por los españoles. En las milpas de hoy, aún se cultivan las cuatro especies de presencia prehispánica y tres de las especies introducidas (el sagú, el aak'il makal y el volador), todas ellas con potencial como fuentes de almidón.

El objetivo del presente trabajo fue la extracción y caracterización fisicoquímica y funcional de almidones de fuentes poco comunes o no convencionales, como el makal (Xanthosoma yucatanensis), el camote (Ipomea batata), la yuca (Manihot esculenta Crantz) y el sagú (Marantha arundinacea), que se cultivan en el estado de Yucatán, México.

\section{Material y métodos}

\subsection{Extracción de almidones}

Para la extracción de los almidones se utilizaron rizomas frescos de makal (Xanthosoma yucatanensis), camote (Ipomea batata), yuca (Manihot esculenta Crantz) y sagú (Marantha arundinacea), los cuales fueron pelados y cortados en cubos de aproximadamente $3 \mathrm{~cm}$ por cada lado y fueron remojados durante 30 minutos en una solución de bisulfito de sodio con una concentración de 1500 ppm, en una relación $1: 3(\mathrm{p} / \mathrm{v})$. Los cubos se molieron en un procesador de alimentos (Moulinex), durante 2 minutos, para reducir el tamaño de partícula. La masa resultante se pasó a unos recipientes que contenían una solución de bisulfito de sodio con una concentración de 1500 ppm de $\mathrm{S}_{2}$, en una relación 1:1 (v/v). La lechada de almidón se filtró en coladores de tela plástica (malla 80 ), para eliminar la fibra, y el filtrado se dejó sedimentar a $4{ }^{\circ} \mathrm{C}$, durante 4 horas. Transcurrido este tiempo, la mayor parte del líquido sobrenadante se eliminó por sifoneo y la lechada de almidón se lavó tres veces con agua destilada, centrifugando en el último lavado a $2500 \mathrm{rpm}$, durante 12 minutos, en una centrífuga Mistral 3000i, con la finalidad de recuperar el almidón. Posteriormente, se secó en una estufa de convección a $55^{\circ} \mathrm{C}$, durante 24 horas, y se molió en un equipo Cyclotec hasta obtener un polvo (malla 100), el cual se almacenó en frascos de plástico con cierre de tapa hermética para su posterior uso (NOVELO-CEN; BETANCUR-ANCONA, 2005).

\subsection{Apariencia microscópica}

La forma y tamaño de los gránulos se determinó por el método de Mac Masters (1964), mediante observación microscópica directa, utlizando microscopio óptico Leica. Se reportaron los diámetros promedio, mayor y menor de los gránulos de almidón.

\subsection{Caracterización química}

La composición proximal se determinó de acuerdo a los métodos oficiales descritos por la AOAC (1997), comprendiendo los siguientes análisis: humedad (método 925.09), proteína cruda (método 954.01), grasa cruda (método 920.39), fibra cruda (método 962.09), cenizas (método 923.03) y carbohidratos totales como Extracto Libre de Nitrógeno (ELN). La determinación de amilosa y amilopectina se realizó con el método colorimétrico 
de Morrison y Laignelet (1983). El contenido de amilopectina se calculó por diferencia al 100\% del contenido de amilosa mediante colorimetría (MORRISON; LAIGNELET, 1983).

\subsection{Caracterización funcional}

\section{Gelatinización}

La temperatura de gelatinización se determinó mediante Calorimetría Diferencial de Barrido (CDB), utilizando un equipo DSC 7 Perkin Elmer, a una velocidad de calentamiento de $10{ }^{\circ} \mathrm{C} /$ minuto, desde 30 a $120^{\circ} \mathrm{C}$. La Temperatura Inicial (Ti), Temperatura Pico (Tp), Temperatura Final (Tf) y la entalpía de gelatinización $(\Delta \mathrm{H})$ se obtuvieron del termograma resultante (RUALES; NAIR, 1994).

\section{Absorción de agua}

La capacidad de absorción de agua se determinó por el método de Anderson et al. (1969). Se prepararon $40 \mathrm{~mL}$ de una suspensión de almidón al 1\% (b.s.), en agua destilada a $30^{\circ} \mathrm{C}$. Se calentaron a una velocidad de $1,5^{\circ} \mathrm{C} /$ minuto hasta alcanzar $60,70,80$ ó $90^{\circ} \mathrm{C}$ y se mantuvieron a esas temperaturas durante 30 minutos con agitación. Se dejaron enfriar a temperatura ambiente y se centrifugaron a $2500 \mathrm{rpm}(2120 \mathrm{x} \mathrm{g})$, durante 15 minutos, en una centrífuga GS-15R (Beckman Instruments, Inc. CA, EUA). El gel resultante se pesó. La capacidad de absorción de agua para cada temperatura se calculó como el peso (g) del gel por g de muestra seca.

\section{Solubilidad y poder de hinchamiento}

Los patrones de solubilidad y poder de hinchamiento de los almidones se determinaron según una modificación del método original de Schoch (1964), realizada por Sathe et al. (1981).

\section{Propiedades de pastificación}

Las propiedades de pastificación de los almidones fueron evaluadas por el método de Wiesenborn et al. (1994). En un vaso de precipitado de $500 \mathrm{~mL}$, se prepararon $400 \mathrm{~mL}$ de una suspensión de almidón al 6\% (b.s.). La suspensión se colocó en un viscoamilógrafo Brabender PT-100 (Alemania). El equipo se operó a una velocidad de $1,5^{\circ} \mathrm{C} /$ minuto, elevando la temperatura inicial de $30^{\circ} \mathrm{C}$ hasta alcanzar $95^{\circ} \mathrm{C}$, y se mantuvo esta temperatura durante 15 minutos. Por último, se descendió la temperatura hasta $50^{\circ} \mathrm{C}$ a una velocidad de $1,5^{\circ} \mathrm{C} /$ minuto y se mantuvo esta temperatura durante 15 minutos. La viscosidad máxima, la consistencia, la fragilidad (breakdown) y el asentamiento (setback), en Unidades Brabender (UB), se calcularon a partir de los amilogramas resultantes.

\section{Claridad de las pastas}

La claridad de las pastas de almidón se evaluó de acuerdo al método de Bello-Pérez et al. (1999), determinando el porcentaje de transmitancia (\%T) a $650 \mathrm{~nm}$ de pastas de almidón al $1 \%(\mathrm{p} / \mathrm{p})$, previamente gelatinizadas y enfriadas a temperatura ambiente.

\section{Firmeza de gel}

La firmeza de los geles de almidón se evaluó mediante el método de Hoover y Senanayake (1995). Para ello, se preparó una suspensión de almidón al $8 \%$ (b.s.) y se calentó en un viscoamilógrafo Brabender a una velocidad de $1,5^{\circ} \mathrm{C} /$ minuto hasta $95^{\circ} \mathrm{C}$. Se mantuvo esta temperatura durante 10 minutos. Se midió la penetración del gel en una máquina universal de pruebas Instron modelo 4411. Cada gel se colocó perpendicularmente en el plato de metal y se comprimió a una velocidad de $1 \mathrm{~mm} /$ segundo, con una probeta de $5 \mathrm{~mm}$, y usando una celda de $5 \mathrm{~kg}$.

\section{Estabilidad a la refrigeración y congelación}

La estabilidad a la refrigeración y congelación se evaluó por una modificación del método de Eliasson y Ryang (1992). Se realizó por gelificación y almacenamiento $4-10^{\circ} \mathrm{C}$, centrifugando y midiendo el agua separada de un gel de almidón en ciclos de un día, durante 5 días.

\subsection{Análisis estadístico}

Los datos obtenidos fueron evaluados mediante medidas de tendencia central y dispersión, así como un análisis de varianza de una vía, siendo los tratamientos las materias primas analizadas (makal, camote, yuca y sagú). Se efectúo una comparación de medias para establecer las diferencias entre las características evaluadas, utilizando el paquete computacional Statgraphics Plus Version 5.1, y de acuerdo a los métodos señalados por Montgomery (2004).

\section{Resultados y discusión}

\subsection{Apariencia microscópica}

Las microfotografías de los gránulos de los almidones de makal, camote, yuca y sagú se muestran en la Figura 1. Los almidones de makal y camote presentaron forma esférica, similares a los almidones de papa, que tienen forma oval a esférica (SWINKELS, 1985) (Tabla 1). Los almidones de yuca mostraron una forma esférica-truncada, similares a los encontrado por Sosa (2003) en dos variedades cubanas de yuca (Manihot esculenta Crantz). El almidón de sagú presentó una forma poligonal, igual a la forma que presenta el almidón de maíz (THOMAS; ATWELL, 1999). El tamaño de los gránulos fue homogéneo, con valores promedio de diámetro de $12,40 \mu \mathrm{m}$ para el makal, $12,41 \mu \mathrm{m}$ para el camote, $16,5 \mu \mathrm{m}$ para la yuca y $10,64 \mu \mathrm{m}$ para el sagú. Dichos valores fueron similares a los encontrados por Forsyth et al. (2002) en diversas variedades de Pachyrhizus ahipa, con un tamaño promedio de 9,34 a 14,63 $\mu \mathrm{m}$. De igual forma, estos valores encontrados en los almidones en estudio están dentro de los intervalos de otros almidones como los de X. sagittifolium $(2,8-50 \mu \mathrm{m})$, camote $(2-72 \mu \mathrm{m})$ y yuca $(3-43 \mu \mathrm{m})$ (MOORTHY, 2002).

\subsection{Caracterización química}

La composición proximal y el contenido de amilosa y amilopectina de los almidones evaluados se muestran en el 

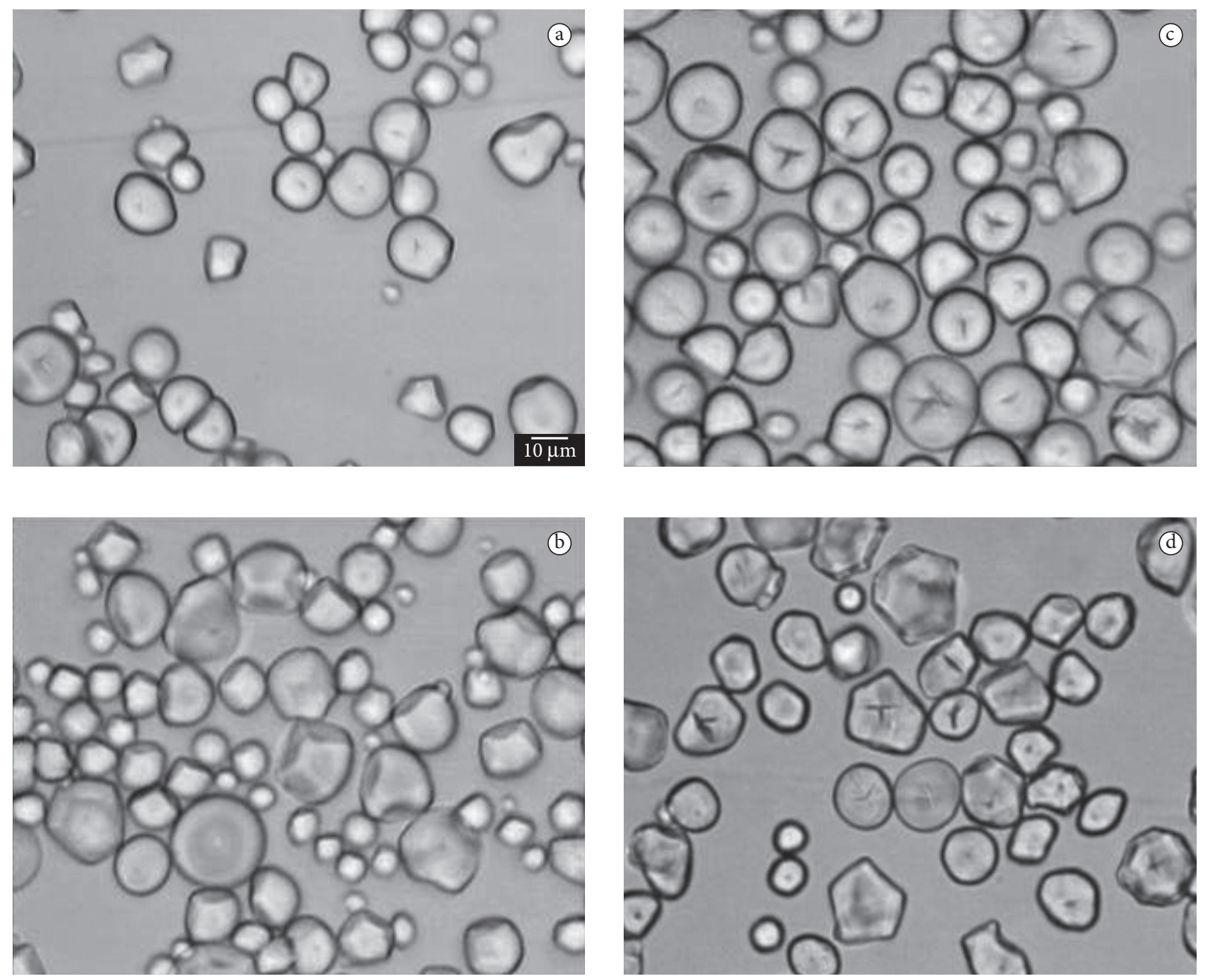

Figura 1. Microfotografías de los gránulos de almidón de: a) makal; b) camote; c) yuca; y d) sagú.

Tabla 1. Tamaño y forma de los gránulos de almidón de makal, camote, yuca y sagú, comparados con diferentes fuentes.

\begin{tabular}{lccc}
\hline Almidones & Promedio $(\mu \mathrm{m})$ & Intervalo $(\mu \mathrm{m})$ & Forma \\
Makal & 12,40 & $8-20$ & Esférica \\
Camote & 12,41 & $8-28$ & Esférica \\
Yuca & 16,50 & $8-22$ & Esférica, truncada \\
Sagú & 10,64 & $4-20$ & Poligonal \\
Maíz $^{1}$ & 15 & $3-26$ & Poligonal \\
Papa $^{1}$ & 33 & $5-100$ & Oval, esférica \\
\hline
\end{tabular}

${ }^{1}$ Swinkels (1985).

Tabla 2. El contenido de proteína de los almidones evaluados mostraron diferencia estadística $(\mathrm{p}<0,05)$. Los contenidos bajos de proteína cruda de los almidones de makal, camote y yuca $(0,16,0,22$ y $0,06 \%$, respectivamente) se encuentran dentro del nivel permitido por la FDA en almidones de maíz (0,35\%), los cuales los hacen factibles para la producción de jarabes con alto contenido de glucosa, evitándose así las reacciones de Maillard que se pueden presentar durante el proceso de producción de estos productos (ZAJAC, 1989). Por lo tanto, el almidón de sagú no es apto para ser utilizado en la elaboración de jarabes, debido a que presentó un mayor contenido de proteína (0.64\%).

Los contenidos de amilosa de los almidones de makal, camote, yuca y sagú fueron de 23,6, 19,6, 17,0 y 22,7\%, respectivamente (Tabla 2), los cuales resultaron ser menores al compararlos con el de maíz (28,3\%). El almidón de camote fue similar al almidón de papa, con un contenido de amilosa de $21 \%$ (BETANCUR-ANCONA et al., 2001). Sin embargo, 
Osundahunsi et al. (2003) encontraron altos contenidos de amilosa en almidones de camote de las variedades blanco y rojo, con un 32,15 y $34,16 \%$, respectivamente. Charles et al. (2005) reportaron que el contenido de amilosa en almidones de diferentes variedades de yuca fue de 15,9 a 22,4\%. Los contenidos de amilopectina de los almidones de makal y sagú (76,4 y 77,3\%, respectivamente) fueron menores alos encontrados en los almidones de camote y yuca $(80,4$ y $83,0 \%$, respectivamente). El contenido de estos dos componentes (amilosa y amilopectina), así como los contenidos de proteína, grasa, fibra, cenizas y ELN, serán determinantes en las características estructurales y funcionales de los almidones, condicionando a estos, a que puedan ser agregados a un alimento en particular.

\subsection{Caracterización funcional}

La temperatura y la entalpía de gelatinización de los almidones evaluados mostraron diferencia estadística $(\mathrm{p}<0,05)$ (Tabla 3). Los gránulos de almidón de makal y sagú presentaron la mayor temperatura de gelatinización $\left(\mathrm{Tp}=78,4\right.$ y $74,9^{\circ} \mathrm{C}$, respectivamente), comparados con los otros dos almidones evaluados, con $\mathrm{Tp}=61,3^{\circ} \mathrm{C}$ para el camote y $\mathrm{Tp}=65,2^{\circ} \mathrm{C}$ para la yuca. Las temperaturas de gelatinización de los almidones de makal y de sagú fueron similares a los reportados por Bello y Tovar (2001) en almidón de dos variedades de camote, con un rango de $\mathrm{Tp}=72,8$ y $78{ }^{\circ} \mathrm{C}$. Por otra parte, Osundahunsi et al. (2003) reportaron valores menores de temperatura de gelatinización en almidones de camote de las variedades blanca y roja, con $\mathrm{Tp}=70,7$ y $71,5^{\circ} \mathrm{C}$, respectivamente. El valor encontrado para el almidón de yuca en estudio fue similar a los valores encontrados para cinco variedades de yuca, con un rango de $\mathrm{Tp}=64,4 \mathrm{a} 69,9^{\circ} \mathrm{C}$ (CHARLES et al., 2005). Debido a esta alta temperatura, los almidones de makal y sagú hacen factible su inclusión en productos que serán sometidos a altas temperaturas de procesamiento, como los productos enlatados. Mientras que los almidones de camote y yuca pueden considerarse para ser usados en productos que no requieran temperaturas elevadas, tales como caramelos tipo chiclosos o natillas, pudines, etc.

En cuanto a las entalpías de gelatinización $(\Delta \mathrm{H})$ (Tabla 3 ), se puede observar que el valor obtenido para el almidón de makal fue de $14,9 \mathrm{~J} . \mathrm{g}^{-1}$, para el camote de $9,2 \mathrm{~J} . \mathrm{g}^{-1}$, para la yuca de $10,0 \mathrm{~J} . \mathrm{g}^{-1} \mathrm{y}$ para el sagú de $12,5 \mathrm{~J} . \mathrm{g}^{-1}$, los cuales fueron similares a los datos reportados por Moorthy (2002) en almidones de Xanthosoma $\left(4-15 \mathrm{~J} . \mathrm{g}^{-1}\right)$, camote $\left(10-18 \mathrm{~J} \cdot \mathrm{g}^{-1}\right)$ y yuca $\left(4-22 \mathrm{~J} \cdot \mathrm{g}^{-1}\right)$. Los valores de entalpía encontrados para los almidones de camote y yuca fueron muy similares a los encontrados por
Osundahunsi et al. (2003) en dos variedades de camote, blanco y rojo (10,5 y 11,0 J.g-1 , respectivamente). Los valores de entalpía menores están relacionados con mayores niveles de amilosa (CZUCHAJOWSKA et al., 1998; SZCZODRAK; POMERANZ, 1992). Sin embargo, esto no sucedió con los almidones de makal y sagú, ya que estos presentaron un mayor contenido de amilosa (23,6 y $22,7 \%$, respectivamente) y su entalpía fue de 14,9 y $12,5 \mathrm{J.g}^{-1}$, respectivamente.

Los patrones de absorción de agua e hinchamiento de los almidones evaluados se muestran en las Figuras 2 y 3, respectivamente. En ellas se puede apreciar que solamente los gránulos del almidón de makal se resisten al hinchamiento a temperaturas menores de $70^{\circ} \mathrm{C}$. Esto es debido a su alta temperatura de gelatinización $\left(72,5^{\circ} \mathrm{C}\right)$, aunque entre los 70 y $90^{\circ} \mathrm{C}$, los gránulos de todos los almidones se hinchan gradualmente a medida que se aumenta la temperatura. Esto es debido a la ruptura de los puentes de hidrógeno intermoleculares de las zonas amorfas, que permiten una absorción irreversible y progresiva del agua (LII et al., 1995). Con respecto al almidón de sagú, éste presentó un comportamiento más semejante al de maíz, ya que el incremento se presentó a partir de los $60^{\circ} \mathrm{C}$. Por otro lado, el almidón de yuca fue el que presentó mayor capacidad de absorción de agua $\left(27,18\right.$ g agua. $\mathrm{g}^{-1}$ almidón) a $90^{\circ} \mathrm{C}$.

El poder de hinchamiento de los almidones es una propiedad de su contenido de amilopectina, siendo la amilosa un diluyente e inhibidor del hinchamiento (CHENG et al., 1996). Debido a lo anterior, el almidón de yuca fue el que presentó mayor poder de hinchamiento $\left(58,83 \mathrm{~g}\right.$ agua. $\mathrm{g}^{-1}$ almidón a $\left.90^{\circ} \mathrm{C}\right)$, con $17 \%$ de amilosa. El makal presentó $28,56 \mathrm{~g}_{\text {agua. }}{ }^{-1}$ almi-

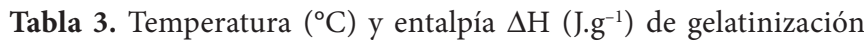
de los almidones de makal, camote, yuca y sagú, comparados con otras fuentes.

\begin{tabular}{|c|c|c|c|c|}
\hline Almidones & $\operatorname{Ti}\left({ }^{\circ} \mathrm{C}\right)$ & $\operatorname{Tp}\left({ }^{\circ} \mathrm{C}\right)$ & $\operatorname{Tf}\left({ }^{\circ} \mathrm{C}\right)$ & $\Delta \mathrm{H}\left(\mathrm{J} \mathrm{g}^{-1}\right)$ \\
\hline Makal & $72,5^{\mathrm{a}}$ & $78,4^{\mathrm{a}}$ & $84,0^{\mathrm{a}}$ & $14,9^{\mathrm{a}}$ \\
\hline Camote & $55,2^{\mathrm{b}}$ & $61,3^{\mathrm{b}}$ & $68,2^{\mathrm{b}}$ & $9,2^{\mathrm{b}}$ \\
\hline Yuca & $57,8^{\mathrm{c}}$ & $65,2^{\mathrm{c}}$ & $75,3^{c}$ & $10,0^{c}$ \\
\hline Sagú & $62,2^{\mathrm{d}}$ & $74,9^{\mathrm{d}}$ & $89,2^{\mathrm{d}}$ & $12,5^{\mathrm{d}}$ \\
\hline X. sagittifolium ${ }^{1}$ & $66-83$ & $69-85$ & $79-90$ & $4-15$ \\
\hline Camote $^{1}$ & $58-75$ & $63-74$ & $78-86$ & $10-18$ \\
\hline Yuca $^{1}$ & 50,68 & $54-78$ & $60-100$ & $4-22$ \\
\hline Maíz ${ }^{2}$ & 62,3 & 66,3 & 72,9 & 10,3 \\
\hline $\mathrm{Papa}^{3}$ & 60 & 69 & 80 & 4,6 \\
\hline
\end{tabular}

a-dLetras diferentes en la misma columna indican diferencia estadística $(\mathrm{p}<0,05) ; \mathrm{NR}=\mathrm{no}$ reportado; ${ }^{1}$ Moorthy (2002); ${ }^{2}$ Betancur (2001); $y^{3}$ Pérez et al. (1998).

Tabla 2. Composición química de los almidones de makal, camote, yuca y sagú, comparados con otras fuentes.

\begin{tabular}{|c|c|c|c|c|c|c|}
\hline Componentes (\%) & Makal & Camote & Yuca & Sagú & Maíz ${ }^{1}$ & $\mathrm{Papa}^{1}$ \\
\hline Humedad & $(8,99)^{\mathrm{a}}$ & $(9,83)^{\mathrm{b}}$ & $(9,48)^{\mathrm{b}}$ & $(10,5)^{c}$ & $(9,9)$ & (19) \\
\hline Proteína cruda & $0,16^{\mathrm{a}}$ & $0,22^{\mathrm{b}}$ & $0,06^{c}$ & $0,64^{\mathrm{d}}$ & 0,10 & 0,06 \\
\hline Grasa cruda & $0,19^{a}$ & $0,31^{\mathrm{b}}$ & $0,20^{\mathrm{a}}$ & $0,36^{\mathrm{b}}$ & 0,35 & 0,05 \\
\hline Cenizas & $0,12^{\mathrm{a}}$ & $0,26^{\mathrm{b}}$ & $0,29^{b}$ & $0,22^{\mathrm{b}}$ & 0,06 & 0,40 \\
\hline ELN & $99,28^{\mathrm{a}}$ & $98,93^{\mathrm{a}, \mathrm{b}}$ & $98,44^{\mathrm{c}}$ & $98,72^{\mathrm{b}, \mathrm{c}}$ & 98,93 & 99,49 \\
\hline Amilosa & $23,6^{\mathrm{a}}$ & $19,6^{\mathrm{b}}$ & $17,0^{c}$ & $22,7^{\mathrm{a}}$ & 28,3 & 21,0 \\
\hline Amilopectina & $76,4^{\mathrm{a}}$ & $80,4^{b}$ & $83,0^{c}$ & $77,3^{\mathrm{a}}$ & 71,7 & 79,0 \\
\hline
\end{tabular}

a-d Letras diferentes en la misma fila indican diferencia estadística $(\mathrm{p}<0,05)$; NR = no reportado; $\mathrm{y}$ Betancur $(2001)$. 
dón, con 23,6\% de amilosa; el camote, 25,53 g agua.g ${ }^{-1}$ almidón, con un contenido de amilosa de 19,6\% y, finalmente, el sagú, $16,98 \mathrm{~g}$ agua. $\mathrm{g}^{-1}$ almidón, con 22,69\% de amilosa. Los valores encontrados para los almidones en estudio se encuentran dentro de los intervalos reportados por Moorthy (2002) para los almidones de yuca (42-71 g agua. $\mathrm{g}^{-1}$ almidón a $95^{\circ} \mathrm{C}$ ), de camote $\left(24,5-27,4 \mathrm{~g}\right.$ agua. $\mathrm{g}^{-1}$ almidón a $\left.85^{\circ} \mathrm{C}\right)$ y del género Xanthosoma (20 g agua. $\mathrm{g}^{-1}$ almidón a $85^{\circ} \mathrm{C}$ ). En cuanto a los patrones de solubilidad que se muestran en la Figura 4 , se puede observar que la solubilidad aumenta conforme se incrementa la temperatura a la que se somete el almidón. Este incremento se da a partir de los $70^{\circ} \mathrm{C}$ para el almidón de makal y se debe a que los gránulos hinchados del almidón permiten la exudación de amilosa (GUJSKA et al., 1994), mientras que el resto de los almidones evaluados presentaron un comportamiento similar, ya que el incremento de la solubilidad se presentó a partir de los $60^{\circ} \mathrm{C}$.

Las propiedades de pastificación de los almidones evaluados se pueden ver en el Figura 5. La viscosidad desarrollada por el almidón de camote fue la más elevada durante el proceso de pastificación (710 UB) y se mantuvo durante las etapas de calentamiento, lo que representa un almidón estable en su espesamiento a los procesos de cocción (Tabla 4). De igual forma,

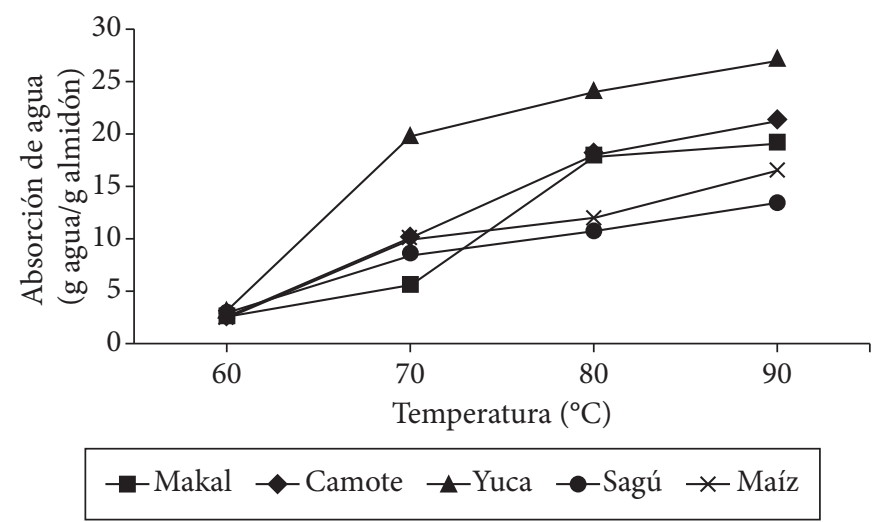

Figura 2. Absorción de agua (g agua.g ${ }^{-1}$ almidón) de los almidones de makal, camote, yuca y sagú, comparados con el maíz.

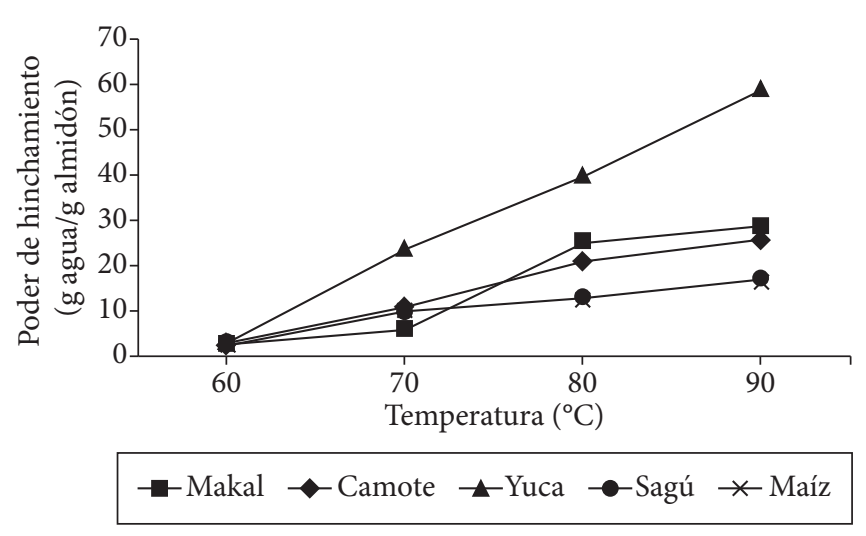

Figura 3. Poder de hinchamiento (g agua. $\mathrm{g}^{-1}$ almidón) de los almidones de makal, camote, yuca y sagú, comparados con el maíz. el almidón de makal presentó un incremento en la viscosidad de 290 UB. Sin embargo, la viscosidad se incrementó cuando la pasta fue enfriada, por lo cual no es estable a los procesos de enfriamiento. Esto debe tenerse en cuenta al momento de pensar en incorporar el almidón a algún producto que necesite enfriamiento durante su preparación. Los valores de consistencia y asentamiento de los almidones de camote y de sagú (10 y 40 UB, y 10 y $70 \mathrm{UB}$, respectivamente), indican una mayor estabilidad a los procesos de calentamiento y enfriamiento. Esto sugiere una alta estabilidad de sus pastas a los esfuerzos mecánicos, tal como lo indican Matos y Pérez (1996), para almidones de yuca.

Los valores de transmitancia (\%T) obtenidos para los almidones de makal, camote, yuca y sagú fueron de 10,9, 24,6, 51,8 y 13,6\% de T, respectivamente (Tabla 5). El makal presentó características similares al plátano criollo $(11,2 \%)$, valor reportado por Bello-Pérez et al. (1999); el camote y la yuca fueron similares a los almidones de maíz normal y maíz ceroso, con 22,6 y 51,2\%, respectivamente (BELLO-PÉREZ, 1995). Novelo y Betancur (2005) mencionan que los almidones que presentan menor cantidad de amilosa son fácilmente dispersados, por lo que se incrementa su claridad, al igual que los que presentan mayor poder de hinchamiento. Esto sucedió con el almidón de yuca, ya que fue el que presentó mayor claridad, con un menor

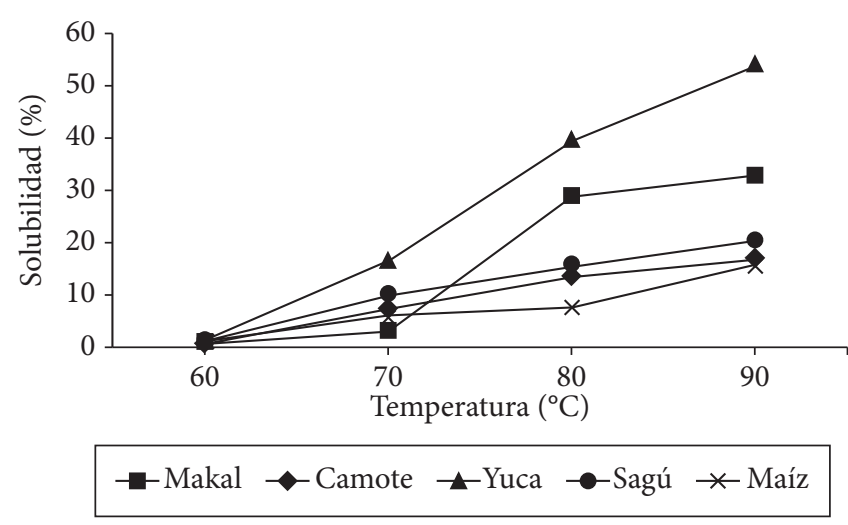

Figura 4. Solubilidad (\%) de los almidones de makal, camote, yuca y sagú, comparados con el maíz.

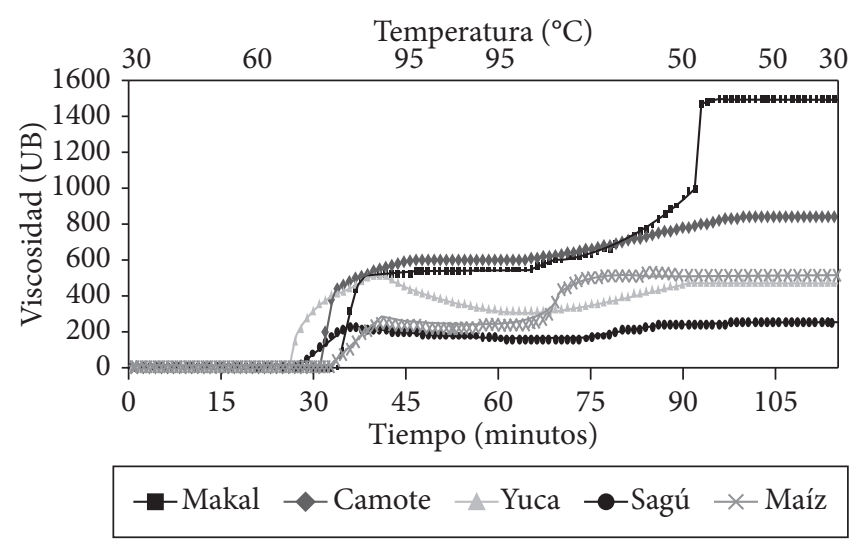

Figura 5. Viscoamilogramas (UB) de los almidones de makal, camote, yuca y sagú, comparados con el maíz. 
contenido de amilosa $(17,02 \%)$ y mayor poder de hinchamiento (58,8 g agua. $\mathrm{g}^{-1}$ almidón). La transparencia u opacidad presentada por las pastas de almidón influyen directamente sobre las características de brillantez y opacidad del color de los productos en los que se empleen como espesantes (BETANCUR-ANCONA et al., 2001). Los almidones que presentaron valores elevados de transmitancia, tales como el de yuca e incluso el de camote podrían ser utilizados en alimentos como mermeladas, gelatinas, y en confitería para la elaboración de gomitas, etc. Mientras que los más opacos, como los de makal y sagú, pueden ser utilizados en alimentos poco transparentes, como las mayonesas, los productos cárnicos, las bebidas concentradas tipo néctar o los productos de panificación.

Los valores de carga máxima y deformación (Tabla 6) encontrados para los almidones en estudio mostraron diferencia estadística $(\mathrm{p}<0,05)$. El almidón de camote mostró la mayor firmeza, con 0,04 kgf; seguido del makal y sagú, con 0,03 kgf para ambos, y, finalmente, de la yuca, con 0,01 kgf. Zhou et al. (1998) señalan que los gránulos de almidón que presentan mayor poder de hinchamiento producen geles que son más deformables que los geles obtenidos de gránulos con menor poder de hinchamiento. Esta capacidad de deformación afecta la firmeza de los geles, encontrándose que los geles menos hinchados desarrollan geles más firmes. Esto sucedió con los almidones de camote y sagú en estudio, ya que estos presentaron la mayor firmeza y tuvieron un bajo poder de hinchamiento (25,53 y 16,98 g agua. ${ }^{-1}$ almidón, respectivamente), comparados con los otros dos almidones en estudio. De igual forma, se pudo observar que los geles de almidón de yuca presentaron la mayor deformación, con $36,18 \%$, mientras que los otros dos almidones presentaron valores más bajos. Estos comportamientos pueden relacionarse con el contenido de amilopectina, ya que a mayor contenido de amilopectina se incrementa el poder de hinchamiento de los almidones y se producen geles más elásticos (ZHOU et al., 1998). De todas maneras, hay que tomar en consideración que las condiciones en que se llevan a cabo la gelatinización y la gelificación de los almidones también influyen sobre esta propiedad (HOOVER; VASANTHAM, 1992).

La evaluación de la estabilidad a la refrigeración y congelación consiste en verificar la expulsión del agua (sinéresis) contenida en los geles como consecuencia de la reorganización de las moléculas del almidón (BETANCUR-ANCONA et al., 2001). El almidón de makal, conforme pasaron los días de almacenamiento, presentó mayor sinéresis en el almacenamiento en refrigeración $\left(4^{\circ} \mathrm{C}\right)$, con $18,6 \%$, y en congelación $\left(-10^{\circ} \mathrm{C}\right)$, con $21,73 \%$, al igual que el almidón de sagú, con 7,2 y 10,3\% (Figuras 6 y 7, respectivamente). Mientras que el almidón de camote presentó sinéresis en el último día de almacenamiento en refrigeración, con 2,17\% de agua expulsada, y en congelación se mantuvo constante durante todo el periodo de almacenamiento, teniendo 7,73\% de agua expulsada en el último día. El almidón de yuca fue el que presentó la mejor estabilidad a los procesos de refrigeración y congelación ( 0 y 3,2\% de sinéresis, respectivamente). Soni et al. (1990) mencionan que cuando los almidones se someten a sucesivos ciclos de congelación, su estructura se ve afectada, ya que hay una redistribución y dilución de las pastas de almidón por el crecimiento y disolución de los cristales de hielo. Este comportamiento se dió en el almidón de makal, por haber presentado una baja estabilidad a los procesos de refrigeración y congelación, ocasionando la pérdida del agua atrapada en el gel. De acuerdo a estos resultados, los almidones de makal y sagú pueden ser utilizados en aquellos alimentos que requieren ser almacenados en refrigeración y necesitan cierta exudación de humedad para proporcionar una apariencia fresca, como los flanes o salsas. Por otra parte, los almidones de camote y yuca, debido a su baja sinéresis, pueden ser utilizados en productos como rellenos de pasteles, alimentos infantiles y sopas.

Tabla 5. Transmitancia (\%) de las pastas de los almidones de makal, camote, yuca y sagú, comprados con otras fuentes.

\begin{tabular}{lc}
\hline Almidón & Transmitancia (\%) a $650 \mathrm{~nm}$ \\
\hline Makal & $10,94^{\mathrm{a}}$ \\
Camote & $24,64^{\mathrm{b}}$ \\
Yuca & $51,76^{\mathrm{c}}$ \\
Sagú & $13,57^{\mathrm{d}}$ \\
Maíz normal $^{1}$ & 22,6 \\
Plátano criollo $^{2}$ & 11,2 \\
\hline
\end{tabular}

a-d Letras diferentes en la misma columna indican diferencia estadística $(\mathrm{p}<0,05)$; 'Bello-Pérez (1995); y ${ }^{2}$ Bello-Pérez et al. (1999).

Tabla 6. Parámetros de deformación y carga máxima de los almidones de makal, camote, yuca y sagú.

\begin{tabular}{lcc}
\hline Almidón & Deformación máxima (\%) & Carga máxima $(\mathrm{kgf})$ \\
\hline Makal & $20,81^{\mathrm{a}}$ & $0,03^{\mathrm{a}}$ \\
Camote & $22,42^{\mathrm{b}}$ & $0,04^{\mathrm{a}}$ \\
Yuca & $36,18^{\mathrm{c}}$ & $0,01^{\mathrm{a}}$ \\
Sagú & $17,90^{\mathrm{d}}$ & $0,03^{\mathrm{a}}$ \\
\hline
\end{tabular}

${ }^{\mathrm{a}-\mathrm{d}}$ Letras diferentes en la misma columna indican diferencia estadística $(\mathrm{p}<0.05)$.

Tabla 4. Propiedades de pastificación de los almidones de makal, camote, yuca y sagú.

\begin{tabular}{|c|c|c|c|c|}
\hline \multirow[t]{2}{*}{ Parámetros } & \multicolumn{4}{|c|}{ Almidón } \\
\hline & Makal & Camote & Yuca & Sagú \\
\hline Temperatura inicial de gelatinización $\left({ }^{\circ} \mathrm{C}\right)$ & 75 & 75 & 65 & 74,5 \\
\hline Viscosidad máxima (UB) & 290 & 710 & 490 & 110 \\
\hline Viscosidad a $95^{\circ} \mathrm{C}$ por 15 minutos (UB) & 300 & 680 & 170 & 270 \\
\hline Viscosidad a $50^{\circ} \mathrm{C}(\mathrm{UB})$ & 470 & 720 & 240 & 450 \\
\hline Consistencia (Breakdown) (UB) & 180 & 10 & -250 & 10 \\
\hline Asentamiento (Setback) (UB) & 170 & 40 & 70 & 70 \\
\hline
\end{tabular}




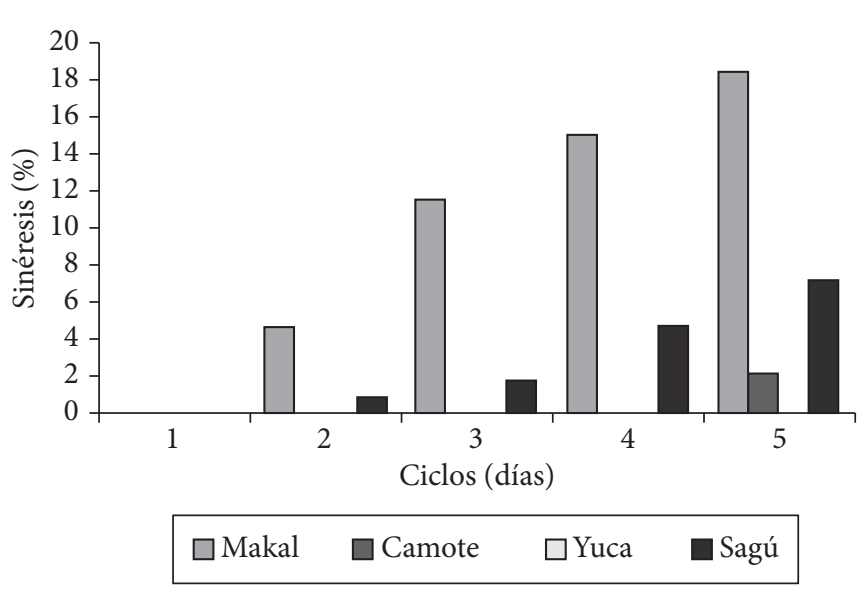

Figura 6. Estabilidad a la refrigeración $\left(4^{\circ} \mathrm{C}\right)$ de los almidones de makal, camote, yuca y sagú.

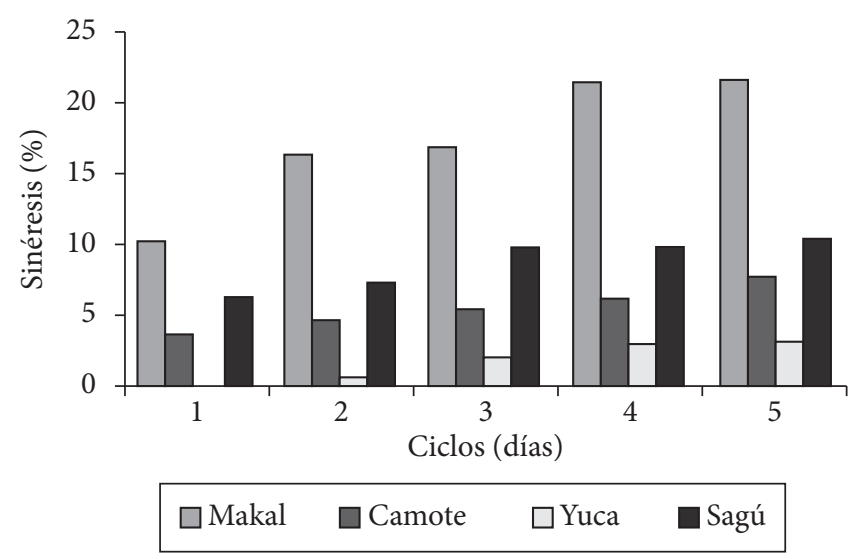

Figura 7. Estabilidad a la congelación $\left(-10^{\circ} \mathrm{C}\right)$ de los almidones de makal, camote, yuca y sagú.

En virtud de que las propiedades funcionales mostradas por los almidones nativos de los tubérculos tropicales fueron en algunos casos mejores al tradicional almidón de maíz, pero similares a las reportadas para las mismas variedades cultivadas en otra parte del mundo, la importancia de este trabajo radica en revalorar aquellos cultivos, como los tubérculos tropicales, que, por diversas razones, han caído en el olvido, pero que por sus componentes tienen un prometedor potencial de explotación. Particularmente, el elevado contenido de almidón presente y la gran versatilidad de propiedades fisicoquímicas encontradas para este polisacárido funcional proveniente de variedades cultivadas en el estado de Yucatán, México, hacen posible la utilización de los recursos naturales de la región, con la finalidad de contar con alternativas propias que permitan evitar, en lo posible, la dependencia del exterior de estos ingredientes alimentarios.

\section{Conclusiones}

Los almidones de tubérculos evaluados mostraron diversas propiedades fisicoquímicas y funcionales que los hacen factibles para su utilización en diversos sistemas alimenticios u otras aplicaciones industriales. El tamaño de los gránulos de los almi- dones de makal, camote y sagú fueron de 12,40, 12,41, y 10,64 $\mu \mathrm{m}$, respectivamente. Excepto el sagú $(0,64 \%)$, los almidones presentaron bajos contenidos de proteína $(0,05-0,22 \%)$, lo cual hace factible su uso en la elaboración de jarabes glucosados. El makal y el sagú, por sus altas temperaturas de gelatinización, podrían ser usados en productos que requieran altas temperaturas, tales como los productos enlatados, alimentos para bebés, etc. El almidón de yuca presentó el mayor poder de hinchamiento (58,83 g agua. $\mathrm{g}^{-1}$ almidón), por lo que podría ser utilizado en productos que requieran retener agua, como los productos cárnicos, como son los embutidos, jaleas, etc. Los almidones de camote y yuca presentaron mayor claridad que los de makal y sagú, por lo que podrían aplicarse en productos de confitería. La firmeza y elasticidad, así como la alta estabilidad a la refrigeración y congelación de los almidones de camote y yuca, indican que podrían utilizarse como agentes espesantes y estabilizantes en sistemas alimenticios que necesiten ser refrigerados y congelados.

\section{Agradecimientos}

Los autores agradecen al Programa de Mejoramiento al Profesorado (PROMEP-SEP) el apoyo financiero para la realización de este trabajo.

\section{Referencias}

ANDERSON, R. et al. Gelatinization of corn grifts by roll and extrusion cooking. Cereal Science Today, v. 14, p. 4-12, 1969.

BELLO-PÉREZ, L.; TOVAR, J. Memorias del Curso: Actualización en Química y Nutrición del Almidón. Yautepec, Morelos: Centro de Desarrollo de Productos Bióticos, Instituto Politécnico Nacional (CEPROBI-IPN), 2001.

BELLO-PÉREZ, L. A. Amilopectina: Caracterización molecular y funcional. Irapuato, Guanajuato, México, 1995. Tesis (Doctorado en Ciencias, Biotecnología de Plantas), Centro de Investigación y Estudios Avanzados del Instituto Politécnico Nacional CINVESTAV-IPN.

BELLO-PÉREZ, L. A. et al. Isolation and partial caracterization of banana starches. Journal of Agricultural and Food Chemistry, v. 47, n.3, p. 854-857, 1999.

BETANCUR-ANCONA, D. Caracterización Molecular, Nutricia y Funcional de Almidones de Phaseolus lunatus y Mucuna pruriens. México, 2001. Tesis (Doctorado en Ciencias, Alimentos), Instituto Politécnico Nacional, Escuela Nacional de Ciencias Biológicas.

BETANCUR-ANCONA, D. et al. Physicochemical and functional characterization of baby lima bean (Phaseolus lunatus) starch. Starch/Stärke, v. 53, n. 5, p. 219-226, 2001.

BETANCUR-ANCONA, D.; GALLEGOS-TINTORÉ, S.; CHELGUERRERO, L. Wet-fractionation of Phaseolus lunatus seeds: partial characterization of starch and protein. Journal of the Science and Food Agriculture, v. 84, n. 10, p. 1193-1201, 2004.

BILIADERIS, C. G. Structures and paste transitions of starch in food systems. Food Technolology, v. 46, n. 6, p. 98-109, 1992.

CHARLES, A. L. et al. Influence of amylopectin structure and amylose content on the gelling properties of five cultivars of cassava starches. Journal of Agricultural and Food Chemistry, v. 53, n. 7, p. 2717-2725, 2005. 
CHENG, Y.; TSAI, M.; TSENG, K. Effect of amylose content on the rheological property of rice starch. Cereal Chemistry, v. 73, n. 4, p. 415-420, 1996.

CIAT - Centro Internacional de Agricultura Tropical. Métodos para Agregar Valor a Raíces y Tubérculos Alimenticios. Manual para el desarrollo de Productos, v. 3, p. 7-12. Colombia, 1997.

CZUCHAJOWSKA, Z. et al. Structure and functionality of barley starches. Cereal Chemistry, v. 75, n. 5, p. 747-754, 1998.

EERLINGEN, R. C.; DELCOUR, J. A. Formation, analysis, structure and properties of type III enzyme resistant starch. Journal of Cereal Science, v. 22, n. 2, p. 129-138, 1995.

ELIASSON, A. C.; RYANG, H. K. Changes in rheological properties of hydroxipropyl potato starch paste during freeze-thaw treatments. Journal of Texture Studies, v. 23, n. 3, p. 279-296, 1992.

FAOSTAT. Food and Agriculture Organization of the United Nations. FAO Database. Roma, Italy, 2001.

FORSYTH, L. J. et al. Characterization of starch from tubers of yam bean (Pachyrhizus ahipa). Journal of Agricultural and Food Chemistry, v. 50, n. 2, p. 361-367, 2002.

GUAN, J.; HANNA, A. M. Extruding foams from corn starch acetate and native corn starch. Biomacromolecules, v. 5, p. 2329-2339, 2004.

GUJSKA, E.; REINHARD, W. D.; Y KHAN, K. Physicochemical Properties of Field Pea, Pinto and Navy Bean Starches. Journal of Food Sciencie, v. 59, n. 3, p. 634-636, 1994.

HOOVER, R.; SENANAYAKE, S. Composition and physicochemical properties of oat starches. Food Research International, Canadá, v. 28 , n. 1, p. 15-26, 1995.

HOOVER, R.; VASANTHAM, T. Effect of defatting on starch structure and physicochemical properties. Food Chemistry, v. 45, n. 5, p. 337-347, 1992.

HORWITZ, W. (Ed.). Official Methods of Analysis. 17 ed. Washington, DC: AOAC, 1997.

KNUTZON, C. A.; GROVE, M. J. Rapid method for estimation of amylose in maize starches. Cereal Chemistry, v. 71, n. 5, p. 469, 1994.

LII, C.; SHAO, Y.; TSENG, K. Gelations mechanism and rheological of rice starch. Cereal Chemistry, v. 72, n. 4, p. 393-400, 1995.

MAC MASTERS, M. M. Microscopic techniques for determining starch granule properties. Whistler, L. R.; Smith, J. R.; BeMiller, N. J. (Ed.). In: Methods in Carbohydrate Chemistry. London: Academic Press, 1964. p. 233-240.

MATOS, M. E.; PÉREZ, E. Preparación y caracterización fisicoquímica y reológica de almidones de yuca modificados químicamente por fosfatación, acetilación y doble derivación. In: Memorias de la conferencia internacional almidón propiedades fisicoquímicas, funcionales, nutricionales y usos. Quito, Ecuador: Escuela Politécnica Nacional, 1996.

MONTGOMERY, C. D. Diseño y Análisis de Experimentos. 2 ed. México: Editorial Limusa S. A. de C. V., 2004. p. 21-125.

MOORTHY, S. Physicochemical and functional properties of tropical tuber starches. Starch/Stärke, v. 54, p. 559-592, 2002.

MORRISON, W. R.; LAIGNELET, B. An improved colorimetric procedure for determining apparent and total amylose in cereal and other Starches. Journal of Cereal Science, v. 1, p. 19-35, 1983.
NOVELO, C. L.; BETANCUR, A. D. Chemical and functional properties of Phaseolus lunatus and Manihot esculenta starch blends. Starch/Stärke, v. 57, n. 9, p. 431-441, 2005.

OSUNDAHUNSI, F. O.; FAGBEMI, T.N.; KESSELMAN, E.; SHIMONIE. Comparison of the physicochemical properties and pasting characteristics of flour and starch from red and white sweet potato cultivars. Journal of Agricultural and Food Chemistry, v. 51, n. 8, p. 2232-2236, 2003.

PÉREZ, E. E.; BREENE, W. M.; BAHNASSEY, Y. A. Variation in the gelatinization profiles of cassava, sago and Arrowroot native starches as measured with different thermal and mechanical methods. Starch/Stärke, v. 50, n. 2-3, p, 70-72, 1998.

RUALES, J.; NAIR, B. Properties of starch and dietary fiber in raw and processed quinoa (Chenopodium quinoa, Wild) seeds. Plants Foods for Human Nutrition, v. 45, n. 3, p. 223-246, 1994.

SATHE, S. K.; SALUNKHE, D. K. Isolation, partial characterization and modification of the Great North bean (Phaseolus vulgaris) starch. Journal of Food Science, v. 46, n. 4, p. 617-621, 1981.

SCHOCH, J. T. Swelling power and solubility of granular starches. In: Whistler, L. R.; Smith, J. R.; BeMiller, N. J. (Eds.). Methods in Carbohydrate Chemistry. London: Academic Press, 1964. p. 106-113.

SONI, P.; SHARMA, H.; SRIVASTA, H.; GHARIA, M. Physicochemical properties of Canna edulis starch: comparison with maize starch. VCH Verlagsgesellschaf mbh. D-6940, 4-8. Germany: [s.n], 1990.

SOSA, M. O. Caracterización fisicoquímica y funcional del almidón de dos variedades cubanas de Manihot esculenta Crantz. Mérida, Yucatán, México, 2003. Tesis - (Licenciatura en Química Industrial), Facultad de Química, Universidad Autónoma de Yucatán.

SWINKELS, J. J. M. Sources of starch, Its Chemistry and Physic. In: Starch Conversion Technology. New York: Marcel Dekker, 1985. p. 15-46.

SZCZODRAK, J.; POMERANZ, Y. Starch-lipid interactions and formation of resistant starch in high-amylose barley. Cereal Chemistry, v. 69, n. 3, p. 626-632, 1992.

THOMAS, H. D.; ATWELL, W. A. Starches. Practical guides for the food industry. American Association of Cereal Chemist. St. Paul Minnesota, USA: Egan Press, 1999. p. 1-87.

WANG, L. Z.; WHITE, P. J. Structure and physicochemical properties of starches from oats with different lipid content. Cereal Chemistry, v. 71, n. 5, p. 443-450, 1994a.

WANG, L. Z.; WHITE, P. J. Structure and properties of amylose, amylopectin and Intermediate materials of oat starches. Cereal Chemistry, v. 71, n. 5, p. 263-268, 1994 b.

WIESENBORN, D. et al. Potato starch paste behavior as related to some physical/chemical properties. Journal of Food Science, v. 59, n. 3, p. 644-648, 1994.

ZAJAC, P. Almidón de maíz, obtención y utilización. Cuba: [s.n], 1989. Editorial Científico, Técnica, p. 92-113.

ZHAO, J.; WISTLER, R. L. Spherical aggregates of starch granules as flavor carriers. Food Technology, v. 48, n. 7, p. 104-105, 1994.

ZHOU, M. et al. Structure and pasting properties of oat starch. Cereal Chemistry, v. 75, n. 3, p. 273-281, 1998.

ZOBEL, H. F. Molecules to granules: A comprehensive starch review. Starch/Stärke, v. 40, n. 2, p. 41-50, 1988. 